\title{
Konfeksiyon İşletmesinin Verimliliği için İş Etüdü Tekniği Kullanımı
}

\author{
Zehra KUMAŞ ${ }^{1}$, Emel Ceyhun SABIR ${ }^{* 1}$, Pınar DURU BAYKAL ${ }^{1}$ \\ Ç.Ü. Mühendislik-Mimarlık Fakültesi, Tekstil Mühendisliği Bölümü, Adana
}

Geliş tarihi: 18.01.2016 Kabul tarihi: 26.05.2016

\section{Özet}

Bu çalışmada seçilmiş bir konfeksiyon işletmesinde İş Etüdü çalışması yapılmıştır. Çalışma kapsamında bir pantolon üretim süreci incelenmiştir. Çalışmada amaç; konfeksiyon işletmelerinde seçilmiş bir ürün için üretimdeki tüm işlerin dizgisel olarak kaydedilmesi ve verimsiz sürelerin ortadan kaldırılmasının araştırılmasıdır. İş etüdü metodu seçilen pantolon üretim süreci için konfeksiyon işletmesinin tüm proseslerine uygulanmıştır.

Anahtar Kelimeler: İş etüdü, Konfeksiyon, Verimlilik, Üretim yönetimi

\section{The Using of Work Study Technique for Process Productivitiy of Apparel Plant}

\begin{abstract}
In this study, Work Study has been done at a selected apparel company. A pants manufacturing process were examined. The purposes of the study are registering for typographical all jobs for a selected product in its manufacturing and investigating the elimination of unproductive times in the garment plants. Work study methods were applied to the entire process of garment enterprises selected for trousers production process.
\end{abstract}

Keywords: Work study, Apparel, Productivity, Production management

* Yazışmaların yapılacağı yazar: Emel Ceyhun SABIR, Mühendislik Mimarlık Fakültesi, Tekstil Mühendisliği Bölümü, Adana. emelc@cu.edu.tr 


\section{GíRiş}

Günümüzde verimlilik rekabetin en önemli unsurlarından birisi haline gelmiştir. Verimlilik kavramının bu denli öneme sahip oluşu hazır giyim işletmelerinde verimsizliği ortaya çıkaran nedenlerin araştırılması ve devamında bunların çözümüne yönelik çalışmalar yapılmasını zorunlu hale getirmiştir. Verimlilik kavramının öneminin giderek artması verimlilik ölçümüne de gereken önemin verilmesini sağlamıştır. İşletmeler yönünden verimliliğin doğru olarak ölçülebilmesi kaynakların etkin olarak kullanılıp kullanılmadığını göstermesi yönünden önemlidir [1]. Kaynaklar her geçen gün azalırken, ihtiyaçlar sürekli olarak artmaktadır. $\mathrm{Bu}$ da işletmelerde kaynakların verimli kullanılması gereğini arttırmaktadır [2].

Tüm işletmelerde olduğu gibi hazır giyim işletmelerinde de verimsizliği ortaya çıkaran 3 temel faktör söz konudur. Bunlar üretim faktörleri olarak adlandırılan; insan, makine ve malzeme olarak siralanabilir. Üretim faktörlerinin birbirleriyle etkileşim halinde bulunmaları süreci incelendiğinde bu faktörlerin her birinin ayrı ayrı optimum verimliliği sağlayacak şekilde bir araya gelmeleri gerekmektedir. Çünkü her durumda bu 3 faktörden birinde karşılaşılan sorun diğerlerinin de verimliliğini olumsuz yönde etkileyecektir [3]. Uygulamada, verimlilik artışı sağlamaya yönelik pek çok etkili yöntem mevcuttur. İş etüdü tekniği, bu tekniklerden biridir ve bünyesinde "Metot Etüdü" ve "İş Ölçümü” tekniklerini barındırmaktadır. İş etüdü, üretim faktörlerinin kullanım etkinliğini yükseltmekte ve özellikle emeğin verimliliğini arttırmada yaygın şekilde kullanılmaktadır. Ayrıca zaman etüdü tekniğinin maliyetinin oldukça düşük olmasına karşın yüksek verimlilik artışları sağlayabilmesi de bu tekniği özellikle küçük boyutlu işletmeler için gerekli ve faydalı kılmaktadır [2].

İş etüdü çok az bir sermaye ile veya hiç sermaye yatırımı yapmaksızın, belirli miktardaki kaynaklardan elde edilecek çıktı miktarını arttırmaya yönelik çalışmalar için kullanılmaktadır. Metot etüdü, insanın performans ve gereksinimlerini de dikkate alarak, iș sistemlerinin amaca uygun organizasyonu yoluyla, insan, üretim aracı ve üzerinde çalışılan nesne arasında göreve uygun bir ortak etkimenin sağlanmasıdır. İş ölçümü ise; nitelikli bir işçinin, belli bir işi, standart bir çalışma hızıyla yapması için gereken zamanı saptamak amaciyla geliştirilmiş tekniklerin uygulanmasıdır [4]. İş etüdü çalışmalarında iş kapsamının çok iyi belirlenmesi gerekir. Kapsam net olarak ortaya konulduğunda incelenen sistemin tüm bileşenlerini belirlemek daha kolay olacaktır [5]. Konfeksiyon işletmelerinde; montaj hattı dengeleme, verimlilik, standart zaman ilişkisi konularında iş etüdü tekniğinin kullanıldığı görülmektedir.

Cömert M., Doba Kadem (2015), çalıșmalarında seçilmiş bir konfeksiyon işletmesinde farklı desenli iki çift pantolonun dikim prosesini incelemişlerdir. Giysilerin dikim hattı için zaman ölçümü ve proses analizi yapılmıştır. Pitch time hesaplanmış, Pitch şeması oluşturulmuş, proses analizinde dar boğazlar tespit edilmiş ve ilgili çözüm önerileri sunulmuştur [6]. Duru Baykal ve Tunç (2011), çalışmalarında bornoz üretiminin dikim sürecinde zaman ölçümü ve proses analizi yapmışlardır. Pitch Time hesaplanmış, Pitch şeması oluşturulmuş, proses analizinde dar boğazlar tespit edilmiştir. Dar boğazların giderilmesine ve dikim bandı verimliliğinin artırılmasına yönelik çözüm önerileri sunulmuştur [7]. Sabır ve Dönmez (2013), iplik işletmesinde verimlilik çalışmasında iş etüdü tekniğini kullanmışlardır. Etüt sonunda ring prosesinin iş kapsamının \%80 azaltılabileceği öneriler ortaya konmuştur [8]. Eryürük (2005), çalışmasında bir konfeksiyon işletmesinde iki adet sezgisel yöntem kullanarak montaj hattı dengeleme yaparak verimlilik düzeyini yükseltmiştir [9]. Çağan (2007), çalışmasında hazır giyim sektöründe standart zaman-verimlilik ilişkisi ve bilgisayar destekli standart zaman tespiti çalışmalarını karşılaştırarak değerlendirmiştir [10].

$\mathrm{Bu}$ çalışmada seçilmiş bir konfeksiyon işletmesinde İş Etüdü çalışması yapılmıştır. Çalışma kapsamında bir pantolon üretim süreci bütün olarak incelenmiştir. Çalışmada amaç; konfeksiyon işletmelerinde seçilmiş bir ürün için 
üretimdeki tüm işlerin dizgisel olarak kaydedilmesi ve verimsiz sürelerin ortadan kaldırılmasının araştırılmasıdır.

\section{MATERYAL VE METOD}

\subsection{Materyal}

$\mathrm{Bu}$ çalışmada etüt edilen iş 400'ün üzerinde çalışanı olan bir konfeksiyon işletmesinin tüm aşamalarıdır. İşletmede günlük çalışma süresi 9,5 saat ve haftada 1 gün tatil olup, ayda 24 gün çalışılmaktadır. Konfeksiyon işletmesinin hangi bölümünde iyileştirme-geliştirme yapılmasına karar verebilmek için işletmede kumaşın depoya gelmesinden üretilen ürünlerin sevkiyat aşamasına kadar tüm proseslerdeki amaçlar iş etüdü tekniğine uygun olarak incelenmiştir. Seçilen konfeksiyon işletmesinde üretim iş akış şeması Şekil 1'de verilmiştir. İşletme planlama, kesim, dikim ve son işlemler şeklinde üretim akışına sahiptir.

İşletmenin mevcut makine parkı Çizelge 1 'de verilmiştir.

İş etüdü çalışmasında işletmede incelenen ürün erkek pantolonu olup, modeli şekil 2'de verilmiştir.

Pantolon kumaşı \%97 pamuk, \%3 elastan içeren düz renkte kumaştır. Model; 2 yan cepli, 2 arka çift fleto cepli düz renkte bir erkek pantolonudur. 3840-42-44-46-48 olmak üzere 6 bedende üretim yapılmaktadır. Lacivert, ten rengi, siyah ve açık gri olmak üzere 4 renkte üretim yapılmaktadır.

\subsection{Metod}

Seçilen konfeksiyon işletmesinde iş etüdü tekniği uygulanmıştır. Seçilen iş, pantolon üretimidir. İşle ilgili tüm ana prosesler tespit edilmiş ve kayıt sistemi olarak iş akış diyagramları kullanılmıştır. İş etüdü basamakları Çizelge 2'de verilen sırada uygulanmıştır. Çalışmada iş etüdü için zaman ölçümü yapılmış ancak standart iș süresinin hesaplanması yapılmamıştır. $\mathrm{Bu}$ nedenle çizelgenin 5. basamağı çalışma kapsamı dışında tutulmuştur.

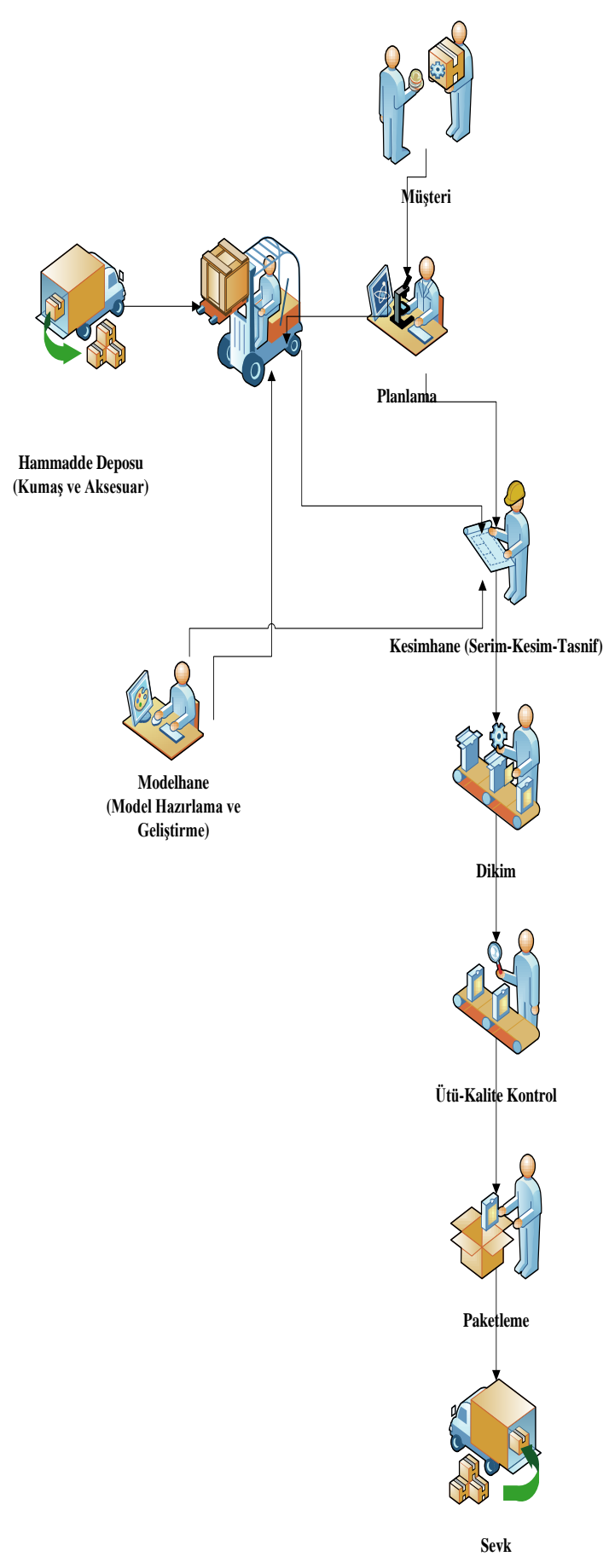

Şekil 1. Üretim iş akış şeması 
Çizelge 1. İşletme makine parkuru

\begin{tabular}{|l|l|c|}
\hline & \multicolumn{1}{|c|}{ Makine Adı } & Makine Sayısı \\
\hline & Pastal Serme Makinesi & 2 adet \\
\hline & Kumaş Serme Makinesi & 1 adet \\
\hline & CUTTER & 1 adet \\
\hline & Kumaş Kesim Hızarı & 2 adet \\
\hline & Pres Makinesi & 2 adet \\
\hline & Pres Ütü & 3 adet \\
\hline & Düz Makine & 149 adet \\
\hline Overlok Makinesi & 44 adet \\
\hline Çift İğne Makinesi & 21 adet \\
\hline Potriz Makinesi & 16 adet \\
\hline Zincir Makinesi & 3 adet \\
\hline Kemer Makinesi & 2 adet \\
\hline Biye Makinesi & 3 adet \\
\hline Göz İlik Makinesi & 5 adet \\
\hline Köprü Otomatı & 4 adet \\
\hline Köprü Makinesi & 5 adet \\
\hline Düz İlik Makinesi & 1 adet \\
\hline Flato Makinesi & 7 adet \\
\hline Pens Makinesi & 2 adet \\
\hline Diğer & 21 adet \\
\hline Vakumlu Üflemeli Ütü & 10 adet \\
\hline Vakumlu Ütü & 21 adet \\
\hline Dikiş Açma Ütüsü & 6 adet \\
\hline Kare Paskara Vakumlu & 10 adet \\
\hline $\begin{array}{l}\text { Kemer Paskarası } \\
\text { Vakumlu }\end{array}$ & 12 adet \\
\hline \multicolumn{2}{|c|}{ TOPLAM } & 353 adet \\
\hline
\end{tabular}

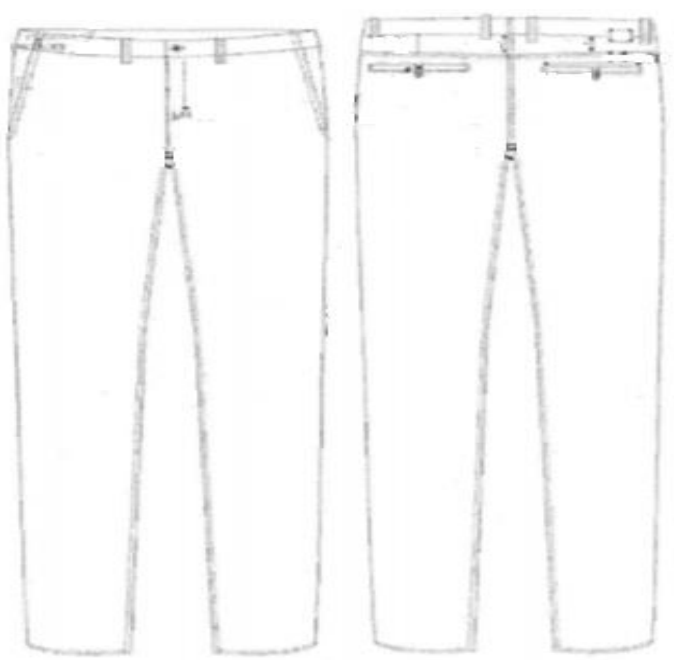

Şekil 2. Erkek pantolon modeli teknik çizimi
Çizelge 2. İs etüdü basamakları [3]

\begin{tabular}{|c|c|c|}
\hline $\begin{array}{l}\text { Sir } \\
\text { a } \\
\text { No }\end{array}$ & İş Etüdü Basamakları & $\begin{array}{l}\text { İş Etüdü } \\
\text { Faaliyetleri }\end{array}$ \\
\hline 1 & $\begin{array}{l}\text { Etüt edilecek işin ya da } \\
\text { sürecin seçilmesi }\end{array}$ & \multirow[b]{3}{*}{$\begin{array}{l}\text {-Seçim } \\
\text {-Kayit } \\
\text {-İnceleme }\end{array}$} \\
\hline 2 & $\begin{array}{l}\text { En uygun kayıt tekniğini } \\
\text { kullanarak } \\
\text { gözlemle, oluşan her olayın } \\
\text { kaydedilmesi }\end{array}$ & \\
\hline 3 & $\begin{array}{l}\text { Kaydedilen olayların } \\
\text { eleştirilerek incelenmesi ve } \\
\text { yapılan her faaliyetin sıras } \\
\text { ile işin amacı, yapıldığ yer, } \\
\text { yapılma sırası, yapan kişi, } \\
\text { yapıldığı yol bakımından } \\
\text { gözden geçirilmesi }\end{array}$ & \\
\hline 4 & $\begin{array}{l}\text { Tüm koşullar göz önünde } \\
\text { bulundurularak en ekonomik } \\
\text { yöntemin geliştirilmesi }\end{array}$ & \multirow{3}{*}{$\begin{array}{l}\text {-Geliştirme } \\
\text {-Ölçüm } \\
\text {-Saptama }\end{array}$} \\
\hline 5 & $\begin{array}{l}\text { Seçilen yöntemin kapsadı̆̆ iş̧ } \\
\text { miktarını ölę̈̈lmesi ve bu } \\
\text { tşin yapłlmast için gerekli } \\
\text { standart } \\
\text { hesaplanmast }\end{array}$ & \\
\hline 6 & $\begin{array}{l}\text { Yeni yöntemin ve bu yöntem } \\
\text { için gerekli zamanın } \\
\text { tanımlanması }\end{array}$ & \\
\hline 7 & $\begin{array}{lr}\text { Yeni yöntem ve } & \text { zamanın } \\
\text { kabul edilmiş } & \text { standart } \\
\text { uygulama } & \text { olarak } \\
\text { düzenlenmesi } & \\
\end{array}$ & \multirow{2}{*}{$\begin{array}{l}\text {-Yerleştirme } \\
\text {-Sürdürme }\end{array}$} \\
\hline 8 & $\begin{array}{l}\text { Yeni standardın iyi bir } \\
\text { denetimle sürdürülmesi }\end{array}$ & \\
\hline
\end{tabular}

İşin mevcut çalışma metoduyla yapılıșına dair bilgilerin kaydı aşamasında işlere ait bilgilerin sistematik bir şekilde toplanmasını sağlamak amacıyla çeşitli tekniklerden (grafik araçlardan) yararlanılır [3]. İş akış şemalarında yapılan etkinliklerin türünü gösteren simgeler Çizelge 3 'de verilmiştir. 
Çizelge 3. İş akış şemaları [3]

\begin{tabular}{|c|l|}
\hline & $\begin{array}{l}\text { İşlem: Süreç, yöntem ya da işlemdeki } \\
\text { asal basamakları gösterir. İşlem } \\
\text { sırasında herhangi bir parça, malzeme } \\
\text { ya da ürün değişikliğe uğrar, düzeltilir. }\end{array}$ \\
\hline & $\begin{array}{l}\text { Yoklama (Muayene): Nitelik ve } \\
\text { nicelikle ilgili olarak yapılan } \\
\text { yoklamaları gösterir. }\end{array}$ \\
\hline & $\begin{array}{l}\text { Taşıma: İş̧ilerin, malzemenin ya da } \\
\text { araçların bir yerden bir yere } \\
\text { hareketlerini ya da taşınmalarını } \\
\text { gösterir. }\end{array}$ \\
\hline & $\begin{array}{l}\text { Gecikme (Boş Bekleme): Olayların } \\
\text { akış1 sırasında oluşan gecikmeleri } \\
\text { gösterir. }\end{array}$ \\
\hline $\begin{array}{l}\text { Sürekli Depolama (Stok): Bir kayıt ya } \\
\text { da yetkiye bağlı olarak malzemenin } \\
\text { depoya girişi ya da çıkışındaki } \\
\text { denetimli bir depolamayı gösterir. }\end{array}$ \\
\hline
\end{tabular}

\section{ARAŞTIRMA BULGULARI VE TARTIŞMA}

\section{1. İşin Tanımı}

Etüt çalışması kumaş depo, modelhane, kesimhane, dikimhane, ütü-kalite kontrol ve paketleme olmak üzere işletmedeki 6 birime uygulanmıştır. İşletmede bulunan birimlerde gerçekleşen prosesler tek tek doğrudan gözlenerek, proseslerde gerçekleşen her bir işlem için ölçüm yapılmıştır. Genel olarak tüm işlemler için kronometre ile 5 ölçüm yapılarak ortalama süre bulunmuştur. Ayrıca işlemleri gerçekleştiren iş̧̧i sayıları ve cinsiyetleri de gözlemlenmiştir. İşlem yapımı sırasında kullanılan makine, taşıyıcı gibi kaynaklar da gözlemlenerek analiz edilmiştir. İşletmede zaman kaybına neden olan işlemleri ya da gereksiz olan işlemleri iyileştirmek için iş akış şemaları oluşturulmuştur. Yapılan etkinlikler işlem, taşıma, gecikme, yoklama ve depolama olarak ayrılmıştır. İşletmedeki birimler için tek tek iş akış şeması oluşturularak süreçler analiz edilmiştir.

\subsection{Mevcut Durum Etüt Çalışması}

Konfeksiyonda iş etüdü yapılan bu çalışmada incelenen ana prosesler; Kumaş Depo, Modelhane, Kesimhane, Dikimhane, Ütü-Kalite Kontrol, Paketleme şeklindedir. Çalışmada Tablo 3'de verilen semboller kullanılarak Şekil 3'deki gibi etüt tabloları oluşturulmuştur. Her ana prosesteki tüm ana ve alt işlemler tespit edilmiş ve bu tablolara kaydedilmiştir. Kayıt edilen ana proseslerin ve alt proseslerin işlenmiş bulunduğu bu etüt formları çok yer kaplayacağından verilmemiş olup, sadece özet tablolar oluşturulmuştur. Tüm özetler Çizelge 4'de verilmiştir. Çizelge 4'de Çizelge 3 'de gösterilen alt etkinliğin tanım kısmı bulunmamakta olup, sadece alt işlem (operasyon) sayısı yer almaktadır. Veriler çok fazla olduğundan bu yola gidilmiştir. Çizelge 4'de işlem türü kısmında sadece ana işlemin türü işaretlenmiştir. Ana ve alt işlemlerin tümü için elde edilen detaylı bilgiler ise Çizelge 5'de görülmektedir.

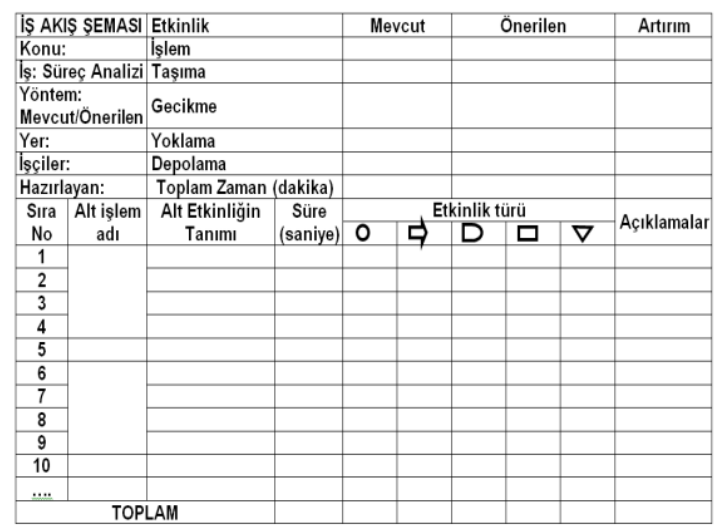

Şekil 3. Etüt formu

Kumaş Depo Mevcut Durum Analizi: Üretilecek model için sipariş edilen kumaş topları kumaş depoda depolanmaktadır. Planlamaya göre belirlenen metrajda kumaşlar depodan karşılanmaktadır. Kumaş depoda toplam 9 etkinlik yapılmakta olup, 6 etkinlik işlemdir. Kumaş toplarının tırdan indirilerek depoya taşınması gerçekleştirilerek 1 taşıma yapılmıştır. Depoya gelen kumaş toplarının kontrolü için kumaş eni ölçülmektedir. Kumaş eni ölçümü ile 1 yoklama yapılmıştır. Kumaş toplarının çıkış işlemi 
yapılana kadar kumaş depoda stoklanmaktadır. Kumaş toplarının depoda beklemesi ile 1 depolama yapılmıştır. Kumaş depoda harcanan toplam zaman 0,89 dakikadır.

Modelhane Mevcut Durum Analizi: Modelhane bölümünden kesimhane bölümüne pastal planı ve kalıp planı verilmektedir. Modele göre planlar bilgisayar programında hazırlanarak çıktısı alınmaktadır. Modelhanede pastal planı hazırlama sırasında 3 işlem gerçekleşmektedir. Pastal planı hazırlama işlemi 120 dakika sürmektedir.

Kesimhane Mevcut Durum Analizi: Kesimhane bölümü serim-kesim-tasnif bölümlerinden oluşmaktadır. Pastal planına göre kumaş depodan kumaş temini yapılmakta ve serim işlemi gerçekleşmektedir. Serilen kumaş katları kesim bölümüne getirilmektedir. Kalıp planına göre kesim işlemi yapılmaktadır. Kesilen parçalar düzenlenmek amacı ile tasnif bölümüne getirilmektedir. Burada kesilen parçalara beden, parti ve kat numarasına göre metolama işlemi yapılmaktadır. Tasnif bölümünde ayrıca telalama işlemi de yapılmaktadır. Tasnif bölümünde mamulü oluşturan tüm parçalar eşlenmektedir. Kesimhanede serim-kesim-tasnif işlemleri sırasında toplam 38 etkinlik gerçekleştirilmektedir. En çok 30 işlem etkinliği yapılmıştır. Kumaş topunun kumaş depodan taşınması ve kesilen parçaların metolamaya ve telalamaya taşınması sırasında 6 taşıma yapılmıştır. Kumaş eni ölçümü ve kesimde ölçüm sırasında 2 yoklama gerçekleştirilmiştir. Gecikme ve depolama etkinlikleri bulunmamaktadır. Kesimhanede toplam zaman 52,82 dakikadır. Burada en çok zaman alan CUTTER'da kesim işlemidir. Makinede kesim işlemi 45 dakika sürmektedir. Diğer işlemler çok zaman almamaktadır.

Dikimhane Mevcut Durum Analizi: Dikim bölümünde bir modeli oluşturan tüm parçaların dikimi ve montajı yapılmaktadır. Dikimhanede dikim işlemleri sırasında çok zaman kaybı olmamaktadır. Dikim işlemi makine ile yapıldığından az zaman almaktadır. Zaman alan işlemler ise parçaların alınması ve işlem gören parçaların bırakılmasıdır. Ayrıca taşıma işlemleri el ile gerçekleştirildiğinden en çok zaman alan işlemler taşıma işlemleri olmuştur. Dikimhanede toplam 294 etkinlik gerçekleştirilmektedir. Bunların 283 adedi işlem olup, 11 taşıma gerçekleştirilmiştir. Dikimhanede harcanan toplam zaman 16,91 dakikadır.

Ütü-Kalite Kontrol Mevcut Durum Analizi: Dikimi tamamlanan giysilere form vermek ve satışa hazır hale getirmek için ütü işlemi gerçekleştirilmektedir. Üretimden çıkan iş beklemeksizin bu bölüme sevk edilip işlem gördükten sonra son kontrol bölümüne gönderilmektedir. Üretimden çıkan giysilere temizlik ve ütü işlemi yapıldıktan sonra son olarak kontrol işlemi yapılmaktadır. Kalite kontrol bölümünde giysiler bir bütün olarak, optik ve teknik olarak, tek tek kontrol edilmekte ve \%100 ölçüm yapılarak paket bölümüne sevk edilmektedir. Ütü-Kalite Kontrol biriminde 14 işlem, 4 taşıma olmak üzere toplam 18 etkinlik gerçekleştirilmektedir. Burada en çok zaman alan işler iplik temizleme ve kalite kontrol işlemleridir. Ürünler bir bütün olarak değerlendirildiğinden temizlik ve kontrol işlemleri zaman alıcı işler olmaktadır. Ütüleme işlemleri en az zaman alan etkinlikler iken, taşıma işlemleri ise daha fazla zaman almaktadır. Dikilen pantolonların taşınması el ile gerçekleştirilmektedir. Ütü-Kalite Kontrol biriminde harcanan toplam zaman 4,19 dakikadır.

Paketleme Mevcut Durum Analizi: Kalite kontrol biriminde kontrolü ve ölçümü yapılan ürünler paketleme bölümüne sevk edilmektedir. Paketleme bölümünde ürünler müşteri isteğine göre katlanarak ambalajlanmakta ya da askılı olarak poşetlenmektedirler. Ürün bir bütün olarak hazırlandıktan sonra kolilenerek yüklemeye hazır hale getirilmektedir. Müşteri isteklerine uygun olarak hazırlanan ürünler kolilenerek ya da askılı olarak yüklenerek sevkiyat işlemi gerçekleşmektedir. Paketleme-Ambalaj biriminde toplam 19 etkinlik gerçekleştirilmektedir. 17 etkinlik işlem olup, 2 etkinlik taşımadır. Burada en çok zaman alan iplik temizleme işlemidir. Ürünler müşteri isteğine göre ambalajlanıp paketlendiğinden dolayı en son kontrol işlemi yapılmakta ve iplik temizleme işlemi zaman 
almaktadır. Diğer zaman alan etkinlik taşımalardır. Taşımalar el ile yapıldığından diğer işlemlere göre zaman alabilmektedir. Paketleme-Ambalaj biriminde harcanan toplam zaman 2,20 dakikadır.

Çizelge 4. Mevcut durum tüm proseslerin iş akışı etüt formu

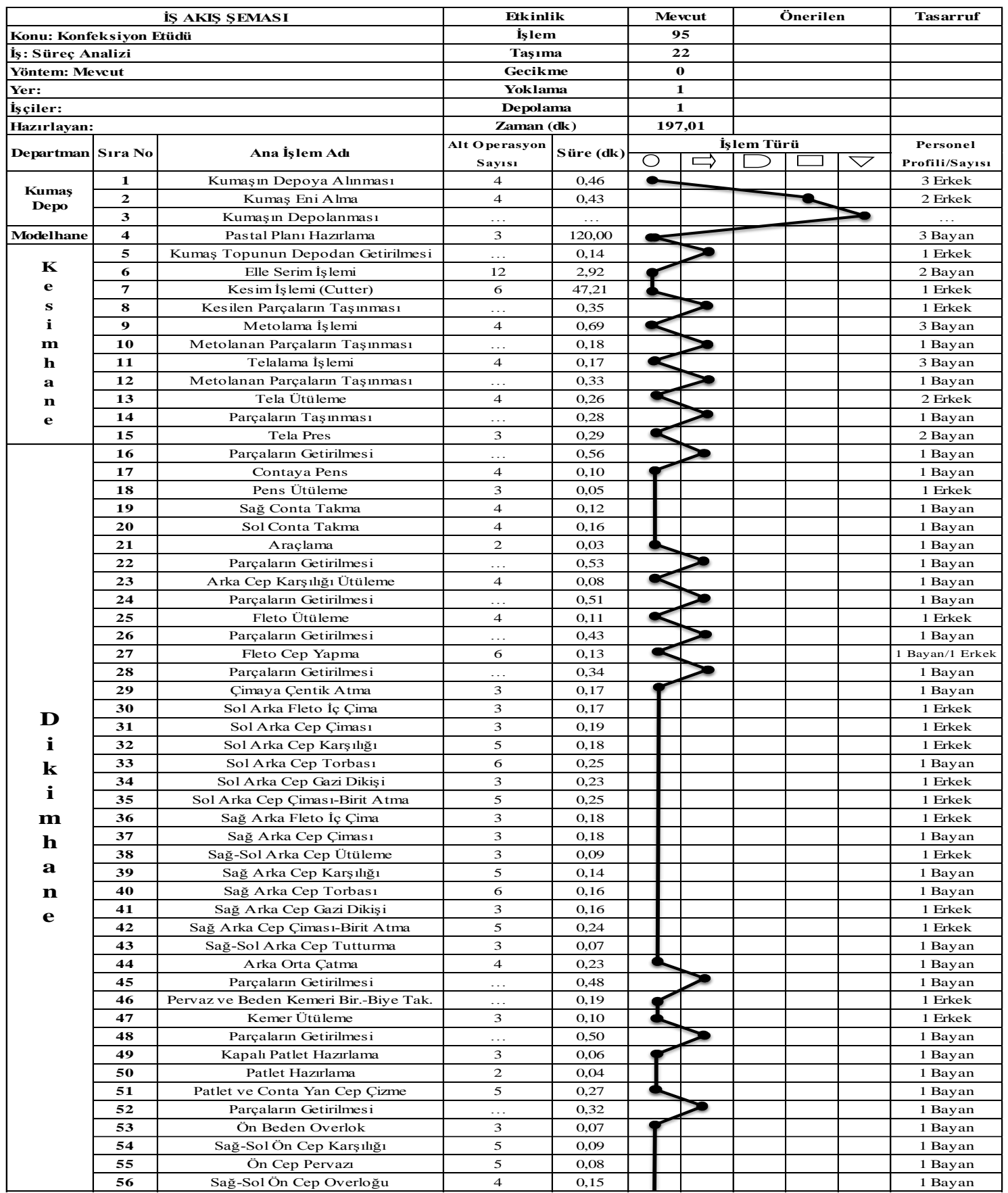


Çizelge 4. Mevcut durum tüm proseslerin iş akışı etüt formu (devamı)

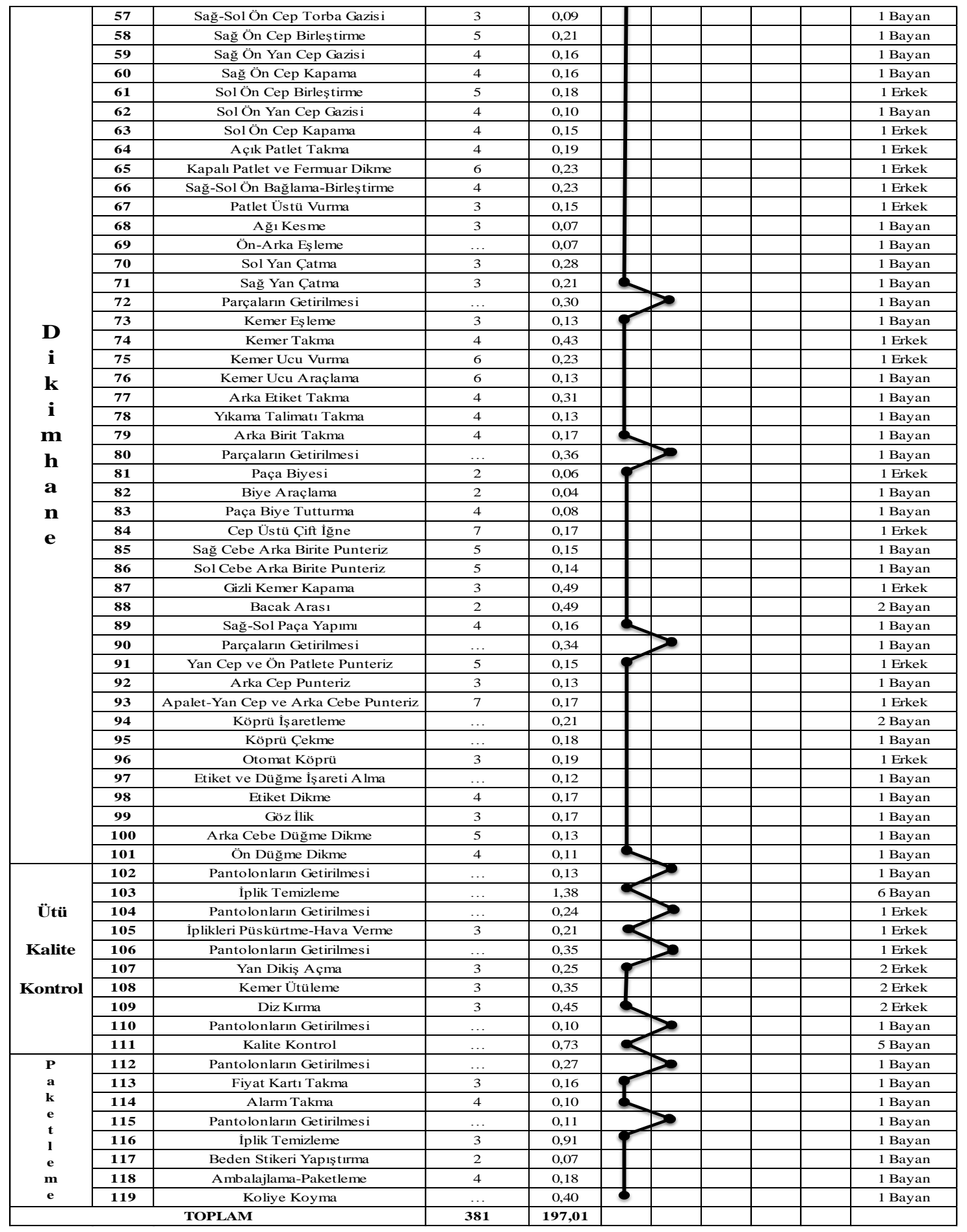


Mevcut sistemin ana prosesleri kendi aralarında karşlaştırılarak sistemin durumu ortaya koyulmuştur (Çizelge 5). Çizelgede ana prosesler, alt işlem sayısı, toplam etkinlik sayısı, etkinlik zamanı, etkinlik türleri ve personel sayısı görülmektedir.

Çizelge 5. Mevcut durum proses karșllaştırma

\begin{tabular}{|c|c|c|c|c|c|c|c|c|c|c|}
\hline \multirow{2}{*}{ No } & \multirow{2}{*}{$\begin{array}{c}\text { Ana Proses } \\
\text { Adı }\end{array}$} & \multirow{2}{*}{$\begin{array}{c}\text { Alt } \\
\text { İşlem } \\
\text { Sayısı }\end{array}$} & \multirow{2}{*}{$\begin{array}{c}\text { Toplam } \\
\text { Etkinlik } \\
\text { Sayısı }\end{array}$} & \multirow{2}{*}{$\begin{array}{l}\text { Süre } \\
\text { (dk) }\end{array}$} & \multirow{2}{*}{$\begin{array}{c}\text { Personel } \\
\text { Sayısı }\end{array}$} & \multicolumn{5}{|c|}{ Etkinlik Türü } \\
\hline & & & & & & İşlem & Taşıma & Gecikme & Yoklama & Depolama \\
\hline 1 & $\begin{array}{c}\text { Kumaş } \\
\text { Depo }\end{array}$ & 3 & 9 & 0,89 & 5 & 6 & 1 & 0 & 1 & 1 \\
\hline 2 & Modelhane & 1 & 3 & 120 & 3 & 3 & 0 & 0 & 0 & 0 \\
\hline 3 & Kesimhane & 11 & 38 & 52,82 & 18 & 30 & 6 & 0 & 2 & 0 \\
\hline 4 & Dikimhane & 86 & 294 & 16,91 & 89 & 283 & 11 & 0 & 0 & 0 \\
\hline 5 & $\begin{array}{c}\text { Ütü- Kalite } \\
\text { Kontrol }\end{array}$ & 10 & 18 & 4,19 & 22 & 14 & 4 & 0 & 0 & 0 \\
\hline 6 & Paketleme & 8 & 19 & 2,20 & 8 & 17 & 2 & 0 & 0 & 0 \\
\hline & Toplam & 119 & 381 & 197,01 & 145 & 353 & 24 & 0 & 3 & 1 \\
\hline
\end{tabular}

Çizelge 5'e göre en çok işlem etkinliği olan ana proses dikimhanedir. En az işleme sahip ana proses ise modelhanedir. En cok taşıma etkinliğinin yapıldı $\breve{g} 1$ ana proses de dikimhanedir. Dikimhane bölümünde 283 işlem ve 11 taşıma etkinliği yapılmıştır. En çok zaman alan proses ise modelhanedir. Şekil 4, ana proseslerin toplam etkinlik sayısı ile etkinlik sürelerini göstermektedir. Etkinlik sayısı ile etkinlik zamanı karşılaş̧ırılmıştır.

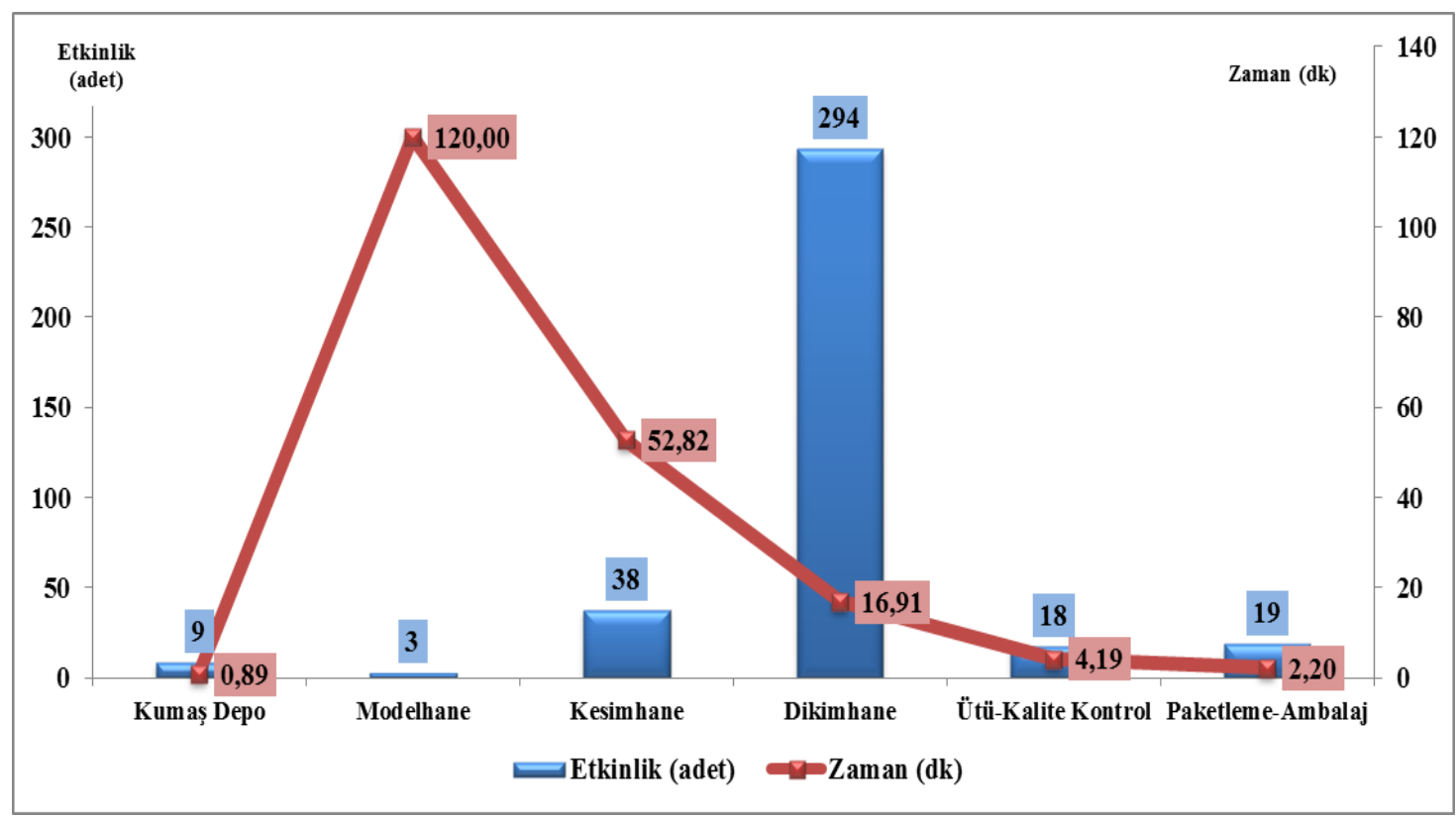

Şekil 4. Etkinlik-Zaman karşılaştırması grafiği 
Grafiğe göre en çok etkinlik dikimhane prosesinde gerçekleşmekte olmasına rağmen, dikim işlemleri çok fazla zaman almamıştır. Modelhane prosesinde etkinlik sayısı az olmasına rağmen toplam etkinlik zamanı ise çok fazladır. Önerilen sistemde dikimhane bölümünde bazı iyileştirmeler yapılarak ölçümleri yapılmıştır. Önerilen sistemde dikimhane prosesinde toplam etkinlik sayıs 285'dir. Önerilen sistemde 274 işlem gerçekleşmekte olup, 11 taşıma yapılmıştır.
Mevcut sistemdeki ana proseslerin iş kapsamı ve etkinlik türleri dikkate alınarak, iyileştirme çalışmasının dikimhanede yapılması gerektiği görülmektedir. Çizelge 6, beş farklı açıdan mevcut durumun değerlendirme sonucunu göstermektedir. Burada, "Başka ne yapılabilir?" sorusu varsa iyileştirme önerilerini ortaya koyacaktır. Önerilen durumda proses karşılaştırması ise Çizelge 7'de verilmiştir.

Çizelge 6. Dikim departmanında eleştirerek inceleme tekniğinin uygulanması

\begin{tabular}{|c|c|c|}
\hline \multirow{4}{*}{ AMAÇ } & Ne yapılıyor? & $\begin{array}{l}\text { Pantolon dikim sürecinde taşımalar genel olarak elle yapılmaktadır. } \\
\text { Operasyonlar üretime göre ön-arka ve birleştirme olmak üzere genel } \\
\text { olarak üç bölüme ayrılmıştır. Bu bölümde sağ-sol kısım dikimi } \\
\text { yapılarak kendi içinde ayrılmıştır. Operasyonlar bölüm bölüm } \\
\text { gerçekleştirilmektedir. }\end{array}$ \\
\hline & $\begin{array}{c}\text { Niçin } \\
\text { yapiliyor? }\end{array}$ & Yapılabilecek en iyi yöntem budur. \\
\hline & $\begin{array}{l}\text { Başka ne } \\
\text { yap1labilir? }\end{array}$ & $\begin{array}{l}\text { Verimlilik sağlaması açısından ve yeni bir maliyet oluşturmaması } \\
\text { açısından işlem sıralarında değişiklik yapılabilir. Böylece zamandan } \\
\text { tasarruf sağlanır. }\end{array}$ \\
\hline & $\begin{array}{l}\mathrm{Ne} \\
\text { yapılmalıdır? }\end{array}$ & $\begin{array}{l}\text { İş, etüt edilerek departmanda yer alan ustabaşı, işçiler ve sorumlularla } \\
\text { ne yapılabileceği hakkında toplantı yapılarak en iyi iş akışı } \\
\text { belirlenmelidir. }\end{array}$ \\
\hline \multirow{4}{*}{$\begin{array}{l}\text { YER VE } \\
\text { ÜRETIMM } \\
\text { ARACI }\end{array}$} & $\begin{array}{l}\text { Nerede } \\
\text { yapiliyor? }\end{array}$ & $\begin{array}{l}\text { Dikim işlemi dikimhane bölümünde büyük bant tipi kullanılarak } \\
\text { yapılmaktadır. }\end{array}$ \\
\hline & $\begin{array}{l}\text { Niçin orada } \\
\text { yapilıyor? }\end{array}$ & $\begin{array}{l}\text { Model tipine uygun şekilde ön ve arka operasyonlar ayrılarak yan } \\
\text { çatma operasyonunda birleşip montaj hattına girmektedir. }\end{array}$ \\
\hline & $\begin{array}{l}\text { Başka nerede } \\
\text { yapılabilir? }\end{array}$ & Her departman ayrı olduğundan en uygun yer burasıdır. \\
\hline & $\begin{array}{c}\text { Nerede } \\
\text { yapılmalıdır? }\end{array}$ & Yapılabilecek en uygun yer şu an yapılan yerdir. \\
\hline \multirow[t]{4}{*}{ SIRA } & $\begin{array}{l}\text { Ne zaman } \\
\text { yapıliyor? }\end{array}$ & $\begin{array}{l}\text { Dikime hazırlık işlemleri bittikten sonra dikim işlemi bölüm bölüm ve } \\
\text { sırasıyla gerçekleştirilmektedir. }\end{array}$ \\
\hline & $\begin{array}{l}\text { Niçin o zaman } \\
\text { yapilıyor? }\end{array}$ & $\begin{array}{l}\text { Ön hazırlık ve arka hazırlık işlemleri bitmeden birleştirme işlemi } \\
\text { yapılamayacağından üretimin eksiksiz gerçekleşebilmesi için belli bir } \\
\text { sıranın takip edilmesi gerekmektedir. }\end{array}$ \\
\hline & $\begin{array}{c}\text { Başka ne } \\
\text { zaman } \\
\text { yapılabilir? }\end{array}$ & $\begin{array}{l}\text { Ön-Arka hazırlık ve birleştirme kısımlarında üretim sırasında aksama } \\
\text { yaşanmayacak şekilde kendi içinde işlem sırası değişimi ve birleştirme } \\
\text { yapılabilir. }\end{array}$ \\
\hline & $\begin{array}{c}\text { Ne zaman } \\
\text { yapılmalidir? }\end{array}$ & $\begin{array}{l}\text { Üretim sırası bozulmayacak şekilde en uygun, verimli olan zamanda } \\
\text { yapılmalıdır. }\end{array}$ \\
\hline
\end{tabular}


Çizelge 6. (devamı)

\begin{tabular}{|c|c|c|}
\hline \multirow{4}{*}{ Kİşİ } & Kim yapıyor? & $\begin{array}{l}\text { Her işi hem bayan hem de erkek yapabilmektedir. Genel olarak } \\
\text { operasyonlarda } 1 \text { işçi çalışmaktadır. }\end{array}$ \\
\hline & $\begin{array}{l}\text { Niçin o kimse } \\
\text { tarafindan } \\
\text { yapilıyor? }\end{array}$ & $\begin{array}{l}\text { Dikim işlemi kişiye göre değişiklik gösterebilmektedir. Bayan veya } \\
\text { erkek olması standart bir süre belirtmemiştir. }\end{array}$ \\
\hline & $\begin{array}{l}\text { Başka kim } \\
\text { yapabilir? }\end{array}$ & Hem bayan işçi hem de erkek işçi yapabilir. \\
\hline & $\begin{array}{l}\text { Kim } \\
\text { yapmalıdır? }\end{array}$ & $\begin{array}{l}\text { Hem bayan hem de erkek işçi yapabilmektedir. Kesim gibi daha zor ve } \\
\text { ağır parçaların taşınması gibi işleri erkek işçilerin yapması daha } \\
\text { uygundur. }\end{array}$ \\
\hline \multirow{4}{*}{ YÖNTEM } & $\begin{array}{c}\text { Nasil } \\
\text { yapiliyor? }\end{array}$ & $\begin{array}{l}\text { Operasyonlar sırası ile gerçekleştirilmektedir. Dikim işlemi sırasında } \\
\text { genel olarak tek el kullanılmaktadır. Sağ el ve sol el birlikte } \\
\text { kullanılmamaktadır. }\end{array}$ \\
\hline & $\begin{array}{l}\text { Niçin o } \\
\text { biçimde } \\
\text { yapıliyor? }\end{array}$ & $\begin{array}{l}\text { Dikim işleminde insan faktörü ön plandadır. İnsan kendi için en uygun } \\
\text { şekilde işlemi gerçekleştirmektedir. }\end{array}$ \\
\hline & $\begin{array}{l}\text { Başka ne } \\
\text { biçimde } \\
\text { yapilabilir? }\end{array}$ & $\begin{array}{l}\text { Üretimden sorumlu kişiler tarafindan işçilere dikim işlemi sırasında } \\
\text { hem sağ el hem de sol eli birlikte kullanması gerektiği, bu şekilde daha } \\
\text { kısa sürede işlemleri gerçekleştirebileceği anlatılıp bu şekilde } \\
\text { uygulama yapılabilir. İşlem sıraları yeniden gözden geçirilip en uygun } \\
\text { işlem akışı belirlenebilir. }\end{array}$ \\
\hline & $\begin{array}{l}\text { Nasıl } \\
\text { yapılmalıdır? }\end{array}$ & $\begin{array}{l}\text { Operasyonlar en verimli olacak şekilde yeniden belirlenerek iş akışı } \\
\text { sağlanmalıdır. İşlemlerin daha ergonomik ve kurallı olması için } \\
\text { dengeli bir şekilde ve en kısa zamanda yapılması sağlanmalıdır. }\end{array}$ \\
\hline
\end{tabular}

Çizelge 7. Önerilen durumda proses karşılaştırma

\begin{tabular}{|c|c|c|c|c|c|c|c|c|c|c|}
\hline \multirow{2}{*}{ No } & \multirow{2}{*}{$\begin{array}{c}\text { Ana Proses } \\
\text { Adı }\end{array}$} & \multirow{2}{*}{$\begin{array}{c}\text { Alt } \\
\text { İşlem } \\
\text { Sayısı }\end{array}$} & \multirow{2}{*}{$\begin{array}{c}\text { Toplam } \\
\text { Etkinlik } \\
\text { Sayısı }\end{array}$} & \multirow{2}{*}{$\begin{array}{l}\text { Süre } \\
\text { (dk) }\end{array}$} & \multirow{2}{*}{$\begin{array}{c}\text { Personel } \\
\text { Sayisı }\end{array}$} & \multicolumn{5}{|c|}{ Etkinlik Türü } \\
\hline & & & & & & İşlem & Taşıma & Gecikme & Yoklama & Depolama \\
\hline 1 & $\begin{array}{c}\text { Kumaş } \\
\text { Depo }\end{array}$ & 3 & 9 & 0,89 & 5 & 6 & 1 & 0 & 1 & 1 \\
\hline 2 & Modelhane & 1 & 3 & 120 & 3 & 3 & 0 & 0 & 0 & 0 \\
\hline 3 & Kesimhane & 11 & 38 & 52,82 & 18 & 30 & 6 & 0 & 2 & 0 \\
\hline 4 & Dikimhane & 84 & 285 & 16,62 & 87 & 274 & 11 & 0 & 0 & 0 \\
\hline 5 & $\begin{array}{c}\text { Ütü- Kalite } \\
\text { Kontrol }\end{array}$ & 10 & 18 & 4,19 & 22 & 14 & 4 & 0 & 0 & 0 \\
\hline 6 & Paketleme & 8 & 19 & 2,20 & 8 & 17 & 2 & 0 & 0 & 0 \\
\hline & Toplam & 117 & 372 & 196,72 & 143 & 344 & 24 & 0 & 3 & 1 \\
\hline
\end{tabular}

Proseslerde gerçekleşen işlemleri daha iyi anlamak için iki el süreç şeması çizilmiştir (Çizelge 8). Burada sağ elin ve sol elin yaptığ işlemler tek tek analiz edilmiştir. Önerilen sistemde iyileştirilen işlemler için iki el süreç şeması hazırlanmıştır (Çizelge 9). 
Çizelge 8. Mevcut sistem dikim işlemi iki el süreç şeması

\begin{tabular}{|c|c|c|c|c|c|c|c|c|c|c|c|c|c|}
\hline \multicolumn{2}{|c|}{ İKI EL SÜREÇ SEMASI } & \multicolumn{4}{|c|}{ Etkinlik } & \multicolumn{3}{|c|}{ Mercut Sol E } & \multicolumn{3}{|c|}{ Mevcut Sağ El } & Önerilen Sol El & Önerilen Sağ E] \\
\hline \multicolumn{2}{|c|}{ Konu: Dikim İșlemi } & \multicolumn{4}{|c|}{ İ̧lem } & \multicolumn{3}{|c|}{12} & \multicolumn{3}{|c|}{10} & & \\
\hline \multicolumn{2}{|c|}{ ịs: Süreç Analizi } & \multicolumn{4}{|c|}{ Taşıma } & \multicolumn{3}{|c|}{0} & \multicolumn{3}{|c|}{0} & & \\
\hline \multicolumn{2}{|l|}{ Yöntem: Mevcut } & \multicolumn{4}{|c|}{ Gecikme } & \multicolumn{3}{|c|}{4} & \multicolumn{3}{|c|}{6} & & \\
\hline \multicolumn{2}{|l|}{ Yer: Dikimhane } & \multicolumn{4}{|c|}{ Yoklama } & \multicolumn{3}{|c|}{0} & \multicolumn{3}{|c|}{0} & & \\
\hline \multicolumn{2}{|l|}{ İşciler: } & \multicolumn{4}{|c|}{ Depolama } & \multicolumn{3}{|c|}{0} & \multicolumn{3}{|c|}{0} & & \\
\hline \multicolumn{2}{|l|}{ Hazzrlayan: } & \multicolumn{4}{|c|}{$\operatorname{Zaman}(\mathbf{d k})$} & \multicolumn{3}{|c|}{0,32} & \multicolumn{3}{|c|}{0,30} & & \\
\hline \multirow{2}{*}{ İlem Adı } & \multirow{2}{*}{ Sol E Tanım } & S̈̈re $(s n)$ & & Simge & & & & & & & Susmofent & Sوŏ Fl Tanum & J̈slem Ad \\
\hline & & Sure (sn) & 다 & D & $\square$ & $\nabla$ & 0 & 디 & $\square$ & $\nabla$ & Sure (sni) & Sağ H Tanım & șlem Aal \\
\hline & Astar alma & 0,84 & $a$ & & & & & & & & $\ldots$ & Boș & \\
\hline Sağ-Sol Ön Cep & Boş & $\ldots$ & & $\geqslant$ & & & & & & & 0,86 & Cep karş̧ liğı alma & Sağ-Sol Ön Cep \\
\hline Karşılığı & Birleştirme & 1,12 & & & & & & & & & 1,12 & Birleștirme & Karşılığı \\
\hline & Dikme & 1,36 & & & & & & & & & 1,36 & Dikme & \\
\hline & Brrakma & 1,36 & & & & & & & & & $\ldots$ & Boș & \\
\hline & Cep karş̧lı̆ı alma & 0,96 & & & & & & & & & $\ldots$ & Boș & \\
\hline Ön Cep & Boş & $\ldots$ & & $>0$ & & & r & & & & 0,82 & \begin{tabular}{|l|} 
Pervaz alma \\
\end{tabular} & Ön Cep \\
\hline Pervazı & Birleştirme & 0,98 & & & & & & & & & 0,98 & Birleştirme & Pervazı \\
\hline & Dikme & 1,46 & & & & & & & & & 1,46 & Dikme & \\
\hline & Brakma & 0,74 & & & & & & & & & $\ldots$ & Boş & \\
\hline & Parça alma & 1,24 & L & & & & & & & & $\ldots$ & Boş & \\
\hline & Boş & $\ldots$ & & 2 & & & $F$ & & & & 1,42 & Patlet alma & \\
\hline Kapalı Patlet ve & Boş & $\ldots$ & & d & & & & & & & 1,72 & Fermuar alma & Kapalı Patlet ve \\
\hline Fermuar Dikme & Birleştirme & 3,80 & P & & & & & & & & 3,80 & Birleștirme & Fermuar Dikme \\
\hline & Dikme & 4,28 & & & & & $\alpha$ & & & & 4,28 & \begin{tabular}{|l|} 
Dikme \\
\end{tabular} & \\
\hline & Briakma & 1,18 & 6 & & & & & & & & $\ldots$ & Boș & \\
\hline
\end{tabular}

İki el süreç şemasında sağ-sol ön cep karşılığı, ön cep pervazı ve kapalı patlet-fermuar dikme prosesleri yer almaktadır. Sol elin yaptığı 12 işlem varken, sağ elin yaptığı 10 işlem vardır. Sol el 4 kez boşta beklerken, sağ el ise $6 \mathrm{kez}$ boşta beklemektedir. Sol elin yaptığ etkinliklerin toplam zamanı 0,32 dakikadır. Să̆ elin yaptığı etkinliklerin toplam zamanı 0,30 dakikadır. Burada sol el să̆ ele göre daha fazla etkinlik gerçekleştirmektedir.

Süreç şemalarından yola çıkılarak mevcut sisteme alternatif önerilen sistem geliştirilmiştir. Alternatif geliştirilen sistem ile gerek görülen bazı işlemler birleştirilmiş, bazı işlemlerde ise sağ el-sol el sistemine göre değişiklik yapılmıştır.

- CCizelge 4'de dikimhane bölümünde 19. sırada yer alan sağ conta takma ve 20. sırada yer alan sol conta takma işlemleri birleştirilerek sağ-sol conta takma işlemi olarak tek bir işlem yapılmıştır.
- Çizelge 4'de dikimhane bölümünde 100. sırada yer alan arka cebe düğme dikme ve 101. sirada yer alan ön düğme dikme işlemleri birleştirilerek arka cebe ve öne düğme dikme işlemi olarak tek bir işlem yapılmıştır.

- Çizelge 8'de görüldüğü gibi mevcut sistemde sağ-sol ön cep karşılığı işleminde astar alma ve cep karşılığı alma etkinlikleri ayrı ayrı gerçekleştirilmektedir. Alternatif önerilen sistemde astar sol el ile cep karşılığ sağ el ile alınarak iki etkinliğin birlikte yapılması sağlanmış ve boş bekleme ortadan kaldırılmıştır.

- Çizelge 8'de mevcut sistemde ön cep pervazı işleminde cep karşılığı alma ve pervaz alma etkinlikleri ayrı ayrı gerçekleştirilmektedir. Alternatif önerilen sistemde cep karşılığ ile pervaz sağ el ile alınarak iki etkinliğin birlikte yapılması sağlanmış ve boş bekleme ortadan kaldırılmıştır. 
- Çizelge 8'de mevcut sistemde kapalı patlet ve fermuar dikme işleminde patlet alma ve fermuar alma etkinlikleri ayrı ayrı gerçekleştirilmektedir. Alternatif önerilen sistemde kapalı patlet sol el ile fermuar sağ el ile alınarak iki etkinliğin birlikte yapılması sağlanmış ve boş bekleme ortadan kaldırılmıştır.

Çizelge 9. Önerilen sistem dikim işlemi iki el süreç şeması

\begin{tabular}{|c|c|c|c|c|c|c|c|c|c|c|c|c|c|c|c|}
\hline \multicolumn{2}{|c|}{ İKİ EL SÜREÇ ŞEMASI } & \multicolumn{5}{|c|}{ Etkinlik } & \multicolumn{4}{|c|}{ Mevcut Sol E } & \multicolumn{3}{|c|}{ Mevcut Sağ E } & Önerilen Sol El & Önerilen Sağ E \\
\hline \multicolumn{2}{|c|}{ Konu: Dikim İşlemi } & \multicolumn{5}{|c|}{ İșlem } & \multicolumn{4}{|c|}{12} & \multicolumn{3}{|c|}{10} & $\begin{array}{r}13 \\
\end{array}$ & 12 \\
\hline \multicolumn{2}{|c|}{ İș: Süreç Analizi } & \multicolumn{5}{|c|}{ Taşıma } & \multicolumn{4}{|c|}{0} & \multicolumn{3}{|c|}{0} & 0 & 0 \\
\hline \multicolumn{2}{|l|}{ Yöntem: Önerilen } & \multicolumn{5}{|c|}{ Gecikme } & \multicolumn{4}{|c|}{4} & \multicolumn{3}{|c|}{6} & $\mathbf{0}$ & 1 \\
\hline \multicolumn{2}{|l|}{ Yer: Dikimhane } & \multicolumn{5}{|c|}{ Yoklama } & \multicolumn{4}{|c|}{$\mathbf{0}$} & \multicolumn{3}{|c|}{0} & $\mathbf{0}$ & $\mathbf{0}$ \\
\hline \multicolumn{2}{|l|}{ İşçiler: } & \multicolumn{5}{|c|}{ Depolama } & \multicolumn{4}{|c|}{0} & \multicolumn{3}{|c|}{0} & 0 & 0 \\
\hline \multicolumn{2}{|l|}{ Hazırlayan: } & \multicolumn{5}{|c|}{ Zaman (dk) } & \multicolumn{4}{|c|}{0,32} & \multicolumn{3}{|c|}{0,30} & 0,32 & 0,31 \\
\hline \multirow{2}{*}{ İşlem Adı } & \multirow{2}{*}{ Sol El Tanım } & & & & Simge & & & & & Simge & & & & & \\
\hline & & Süre (sn) & 0 & $\Rightarrow$ & $D$ & $\square$ & $\nabla$ & 0 & $\Rightarrow$ & $D$ & $\square$ & $\nabla$ & Süre (sn) & Sağ E Tanım & Ișlem Adı \\
\hline & Astar alma & 1,02 & 9 & & & & & 9 & & & & & 1,02 & Cep karşılığ alma & \\
\hline Sağ-Sol Ön Cep & Birleştirme & 1,12 & & & & & & & & & & & 1,12 & Birleştirme & Sağ-Sol Ön Cep \\
\hline Karşılığı & Dikme & 1,36 & & & & & & & & & & & 1,36 & Dikme & Karşılığı \\
\hline & Birakma & 1,36 & & & & & & & & & & & 1,36 & Burakma & \\
\hline & Cep karş llı̆ı alma & 0,96 & & & & & & & & & & & 0,96 & Pervaz alma & \\
\hline Ön Cep & Birleştirme & 0,98 & & & & & & & & & & & 0,98 & Birleştirme & Ön Cep \\
\hline Pervazı & Dikme & 1,46 & & & & & & & & & & & 1,46 & Dikme & Pervazı \\
\hline & Brrakma & 0,74 & & & & & & & & & & & 0,74 & Birakma & \\
\hline & Patlet alma & 1,06 & & & & & & & & & & & 1,06 & Fermuar alma & \\
\hline Kapalı Patlet ve & Parça alma & 0,76 & & & & & & & & & & & $\ldots$ & Boş & Kapalı Patlet ve \\
\hline Fermuar Dikme & Birleştirme & 3,42 & & & & & & & & & & & 3,42 & Birleştirme & Fermuar Dikme \\
\hline & Dikme & 4,12 & & & & & & & & & & & 4,12 & Dikme & \\
\hline & Birakma & 0,94 & 6 & & & & & 6 & & & & & 0,94 & Birakma & \\
\hline
\end{tabular}

Önerilen sistemde sol el işlem sayısı 13 iken, sağ el işlem sayısı ise 12 işlemdir. Sağ el bir kez boşta beklemektedir. Sol elin toplam zamanı 0,32 dakika iken, sağ elin toplam zamanı 0,31 dakikadır. Burada sol el ile sağ elin etkinlik sayısı ve süreleri birbirine çok yakındır.

\section{SONUÇ}

$\mathrm{Bu}$ çalışmada seçilmiş bir konfeksiyon işletmesinde bir pantolon için üretim prosesinin verimlilik analizi iş akış diyagramı ile iş etüdü yapılmıştır. İşletmede kullanılan makinelerde veya işletme genel tesis yerleştirmede herhangi bir değişiklik yapılmamıştır. Etüt işlemi proseslerde uygulanan işlemler üzerinde gerçekleştirilmiş olup işlem sıraları değiştirilmiş veya işlemler birleştirilmiştir. Çalışmada iş etüdü çalışmalarında kullanılan iş akış şemaları ile iki el süreç şemaları kullanılarak iyileştirilmesi gereken işlemler belirlenmiş ve önerilen sistem oluşturulmuştur. Çizelge 9'da görüldüğü gibi dikimhanede işlem bazında 9 etkinlikten tasarruf yapılabilmiştir.

Her bir birimin mevcut sistemi incelenerek dikim bölümünde iyileştirilme yapılmasına karar verilmiştir. Çizelge 10'da görüldüğü gibi, dikim bölümünde mevcut sistemde toplam 294 etkinlik olup, bunların 283'ü işlem 11' $i$ ise taşıma etkinliğidir. Mevcut sistemin toplam zamanı ise 16,91 dakikadır. Önerilen sistem için bazı işlemler kaldırılmış, bazı işlemler ise birleştirilmiştir. Önerilen sistemde toplam 285 etkinlik yapılmıştır. Bu etkinliklerin 274'ü işlem, 11'i ise taşıma etkinliğidir. Önerilen sistemde toplam zaman ise 16,62 dakika olmuştur. Bir adet pantolon üretimi başına 17,40 saniyelik (0,29 dakikalık) iyileştirme yapılmıştır. 1000 adetlik üretimde 290 dakika (yaklaşı 5 saat) şeklinde bir kazanım olacaktır. 
Çizelge 10. Mevcut sistem ve önerilen sistem dikimhane prosesi etkinlik ve zaman karşılaştırması

\begin{tabular}{|c|c|c|c|}
\hline Etkinlik & $\begin{array}{c}\text { Mevcut } \\
\text { Sistem }\end{array}$ & $\begin{array}{c}\text { Önerilen } \\
\text { Sistem }\end{array}$ & Artırım \\
\hline İşlem & 283 & 274 & 9 \\
\hline Taşıma & 11 & 11 & 0 \\
\hline Gecikme & 0 & 0 & 0 \\
\hline Yoklama & 0 & 0 & 0 \\
\hline Depolama & 0 & 0 & 0 \\
\hline $\begin{array}{c}\text { Zaman } \\
\text { (dk) }\end{array}$ & 16,91 & 16,62 & 0,29 \\
\hline
\end{tabular}

Mevcut sistem ile önerilen sistemin sadece iyileştirme yapılan operasyonları iki el etkinlik metoduna göre karşılaştırıldığında (Çizelge 11) dikimhane prosesinde mevcut sistemde sol el 12 işlem yaparken, sağ el ise 10 işlem yapmaktadır. $\mathrm{Bu}$ durumda sol elde 4 gecikme, sağ elde ise 6 gecikme mevcuttur. Önerilen sistemde sol elin ve sağ elin yaptığ 1 işlem sayıları birbirine yakındır. Önerilen sistemde sol el 13 işlem yaparken, sağ el 12 işlem yapmaktadır. Sol elde herhangi bir gecikme olmazken, sağ elde 1 gecikme gerçekleşmiştir.

Çizelge 11. Mevcut sistem ve önerilen sistem dikimhane prosesi iki el etkinlik karşılaştırması

\begin{tabular}{|c|c|c|c|c|}
\hline \multirow{2}{*}{ Etkinlik } & \multicolumn{2}{|c|}{ Mevcut Sistem } & \multicolumn{2}{c|}{ Önerilen Sitem } \\
\cline { 2 - 5 } & Sol El & Sağ El & Sol El & Sağ El \\
\hline İşlem & 12 & 10 & 13 & 12 \\
\hline Taşıma & 0 & 0 & 0 & 0 \\
\hline Gecikme & 4 & 6 & 0 & 1 \\
\hline Yoklama & 0 & 0 & 0 & 0 \\
\hline Depolama & 0 & 0 & 0 & 0 \\
\hline Zaman & 0,32 & 0,30 & 0,32 & 0,31 \\
\hline
\end{tabular}

Çalışma sonucunda ek maliyet gerektirmeden yapılabilecek iyileştirmeler ortaya konmuştur. Maliyete neden olabilecek ancak verimliliği artıracak öneriler ise aşağıda belirtilmiştir.

\section{Öneriler:}

- İşletmede taşıma işlemleri genelde el ile yapılmaktadır. El ile yapılan taşıma işlemleri dikim sırasında çok fazla zaman almaktadır. Taşıma işlemleri için askılı taşıyıcı sistemlerin kullanılması önerilmektedir. Bu çalışmada askılı taşıyıcı sistem için etüt çalışması yapılamamıştır. Ancak önceki çalışmalarda askılı taşı1ı sistemlerin konfeksiyon işletmelerinde zamandan tasarruf sağladığ1 belirtilmiştir. Uygulama yapılan işletmede askılı taşıyıcı sistemlerin süreyi azaltacağı düşünülerek kullanılması önerilmektedir.

- İşletmede bant sistemi düz bant şeklindedir. Burada dikim bandında parçaların alınması sırasında operatörün parçaya uzanması hem zaman alıc1 hem de yorucudur. Bant sisteminde çapraz bant sisteminin kullanılması önerilmektedir. $\mathrm{Bu}$ çalışmada çapraz bant sistemi için etüt çalışması yapılamamıştır. Ancak önceki çalışmalarda çapraz bant sisteminin üretim akışını hızlandırdığg ve operatörü çok fazla yormadığı belirtilmiştir.

- İş etüdü çalışmaları ergonomi ile bir bütünlük göstermektedir. Çalışma alanının ergonomik olması çalışanlar açısından çok önemlidir. Dikim bandında ergonomik sandalyelerin kullanılması, kontrol masalarının ergonomik olması gibi durumlar çalışanın verimini arttıracaktır.

\section{KAYNAKLAR}

1. Kanat, S., Güner, M, 2007. Tekstil ve Konfeksiyon İşletmelerinde Verimlilik Ölçümü, Tekstil ve Konfeksiyon, 17(4), 279283.

2. Oğuz, F., 2007. İşletmelerde Verimlilik Artırımında İş Ölçümü Tekniği ve Bir Uygulama, Gazi Üniversitesi Sosyal Bilimler Enstitüsü İşletme Anabilim Dalı Yüksek Lisans Tezi, Ankara.

3. Kayar, M., 2008. Hazır Giyim İşletmelerinde Verimsizliği Ortaya Çıkaran Nedenlerin Araştırılması ve Bunların Çözümüne Yönelik Alan Çalışması, Marmara Üniversitesi Fen Bilimleri Enstitüsü Tekstil Eğitimi Anabilim Dalı Doktora Tezi, İstanbul.

4. Akal, Z., 2004, İş Etüdü, MPM Yayınları, 29, Ankara.

5. Sabır, E., C., Bebekli, M., Zenbilci, A., 2014. Tekstil Terbiye İşletmesinde İş Akış Diyagramı ile İş Etüdü, Çukurova Üniversitesi 
Mühendislik Mimarlık Fakültesi Dergisi, 29(1), 81-88, Haziran.

6. Cömert, M., Doba Kadem, F., 2015. Dikim Bandında bir Proses Analizinin Uygulaması, Çukurova Üniversitesi Mühendislik Mimarlık Fakültesi Dergisi, 30(1), 151-166, Haziran.

7. Duru Baykal, P., Tunç, M., 2011. Bornoz Dikiminde Üretim Yönetimi Üzerine bir Çalışma, Çukurova Üniversitesi Mühendislik Mimarlık Fakültesi Dergisi, 26(2), 9-17, Aralık.

8. Sabır, E., C., Dönmez, U., 2013. İplik İşletmesinde İş Etüdü Uygulaması, Tekstil ve Mühendis, 20(92), 11-26.

9. Eryürük, S., H., 2005. Bir Konfeksiyon İşletmesinde Montaj Hattı Dengeleme, İstanbul Teknik Üniversitesi Fen Bilimleri Enstitüsü Yüksek Lisans Tezi, Mayıs, İstanbul.

10. Çağan, S., 2007. Hazır Giyim Sektöründe Standart Zaman-Verimlilik İlişkisi ve Bilgisayar Destekli Standart Zaman Tespiti Üzerine bir Araştırma, Gazi Üniversitesi Eğitim Bilimleri Enstitüsü Yüksek Lisans Tezi, Ankara. 
